\title{
Structure Investigation of Hydrogenated Amorphous Silicon by Positron Annihilation
}

\author{
Hiroyuki NASU, Masao WATANABE, Kiyoshi SHIZUMA, Takeshi IMURA, \\ Yukio OSAKA and Hiromi HASAI \\ $\left(\begin{array}{lc}\text { Department of Electrical Engineering, Faculty of Engineering, Hiroshima University } \\ \text { Shitami, Saijo, Higashi-Hiroshima-shi } & 724\end{array}\right)$
}

陽電子消滅法による水素化非晶質シリコンの構造の研究

\author{
那須弘行 ·渡部雅夫・静間 清・井村 健 ·大坂之雄・葉佐井博巳 \\ (広島大学 工学部 電子物性工学大講座)
}

This paper reviews the application of positron annihilation to the structure investigation of amorphous silicon, particularly, hydrogenated amorphous silicon $(a-S i: H)$. Positron annihilation measurement is quite useful to study vacancy type defects or microvoids, and far more sensitive compared with other methods such as X-ray small angle scattering technique and electron microscopy. By analogy with metals, the $\gamma$-ray spectrum radiated by positron annihilation and lifetime of positron of $a-S i: H$ reflect the increase in the density and size of the microvoids resulting from the randomness of the structure and hydrogenation. The preparation conditions, such as deposition rate, substrate temperature and doping of a-Si:H similarly influence the size and the concentration of the microvoids.

[Received April 22, 1987 ; Accepted August 25, 1987]

Key-words : Positron annihilation, Line shape parameters, Positronium, Hydrogenated amorphous silicon $(a-S i: H)$, Plasma-enhanced CVD, Boron-doped a-Si:H

\section{Positron annihilation measurements}

A positron is an antiparticle of an electron. A positron has the same mass of an electron but is positively charged, and emitted from the radioactive sources such as ${ }^{22} \mathrm{Na},{ }^{58} \mathrm{Co},{ }^{64} \mathrm{Cu}$ and ${ }^{68} \mathrm{Ge}$ by $\beta^{+}$- decay. Figure 1 shows the decay scheme of ${ }^{22} \mathrm{Na}$ commonly used as a positron source. The positron beams originally have energy distribution of 0 to $0.5 \mathrm{MeV}$, but immediately thermalized $(\sim 1 \mathrm{ps})$ in a condensed matter. In a short time after the thermalization, these positrons annihilate with electrons, and radiate $\gamma$-rays. The $\gamma$-rays contain the information on the annihilating process of positrons and electrons, the lifetime of positrons and the momentum distribution of electrons. The positron is liable to be trapped in vacancy-type defects or vacancy-like microvoids in the solid because of the relatively small coulombic repulsion. Under the law of conservation of energy and that of momentum, more than one photon are necessary to be radiated from this annihilation and most likely two $\gamma$-rays are emitted. The possibility of one, three or more $\gamma$-rays emitting processes is theoretically below $1 / 100$ compared with the two $\gamma$-rays emitting process.

Generally, the measurements using positron annihilation fall into three main groups: life-



Fig. 1. The decay scheme of ${ }^{22} \mathrm{Na}$.

time, angular correlation of two emitted $\gamma$-rays, and Doppler broadening of $\gamma$-ray spectrum.

Lifetime measurement of positrons is one of these measurements. Since the potential distribution of the positron is just inversive to that of the electron, it preferentially locates away from nuclei and it is easily trapped at vacancy-like defects or microvoids. Even though the electron density becomes higher than usual by the attractive force of the trapped positron, the lifetime of the trapped positrons is definitely longer than that of free positrons. Thus, the observed lifetimes and the relative intensities indicate the size and the relative concentration of defects or microvoids.

Figure 2 shows a typical measurement system for lifetime (Fast-slow coincidence system). ${ }^{2}$ As 


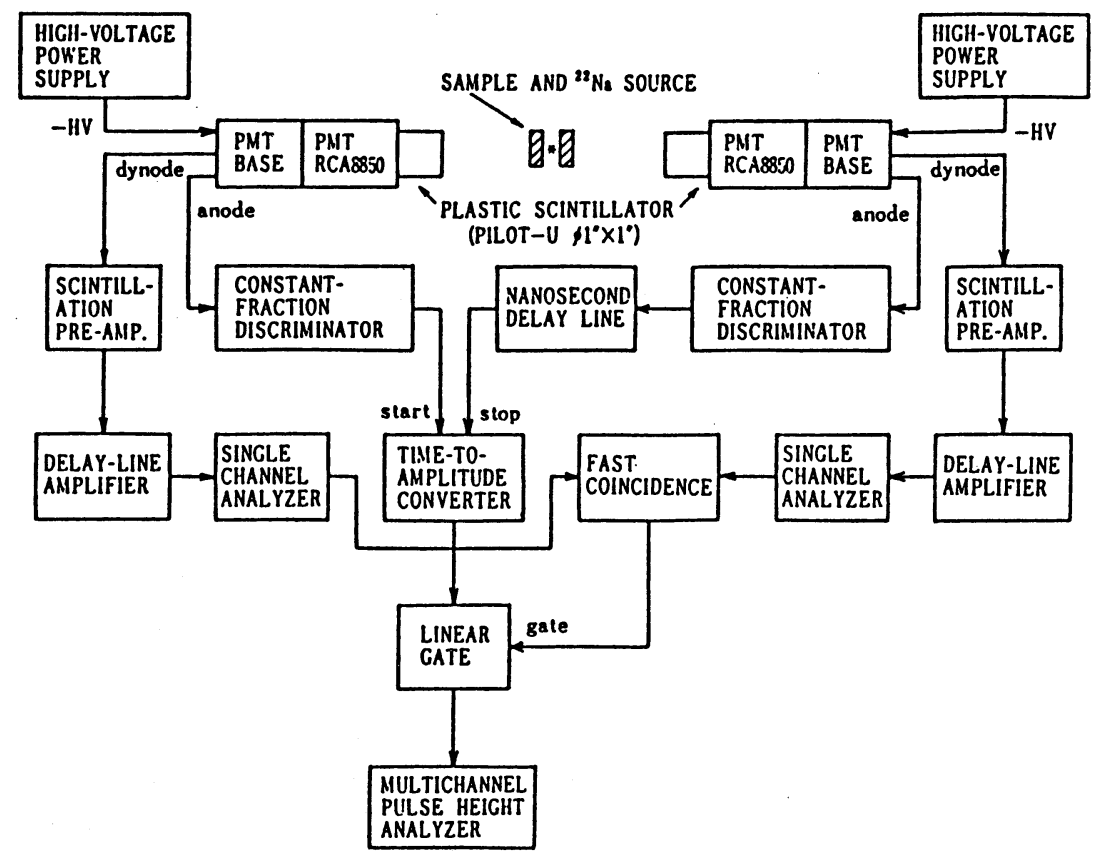

Fig. 2. A typical system diagram for positron lifetime measurement (Fast-slow coincidence system). ${ }^{2)}$

shown in Fig. 1, the transition from ${ }^{22} \mathrm{Na}$ to the first excited state of ${ }^{22} \mathrm{Ne}$ by $\beta^{+}$-decay $(90.5 \%)$ or electron capture $(9.5 \%)$ takes place and then transits to the ground state by emitting $\gamma$-ray of $1.27 \mathrm{MeV}$. The time of emitting this $\gamma$-ray can be considered as the starting time, due to the negligible lifetime of the excited state $(3.7 \mathrm{ps})$ compared with that of common positron lifetime $(\geqq 100 \mathrm{ps}) .{ }^{2), 3)}$ The lifetime of positrons can be estimated from this starting time and the time of detecting $\gamma$-ray with $511 \mathrm{keV}$.

Two $\gamma$-rays emitted by the annihilation propagate roughly in opposite directions. ${ }^{1) 3}$ The momentum of the $e^{+}-e^{-}$pair causes deviation of the angle from the strictly opposite direction $\left(\theta=0^{\circ}\right)$ in the laboratory frame. Figure 3 illustrates the vector diagram of the momentum conservation, and

$$
\theta=P_{\mathrm{T}} / m_{0} c
$$

where $\theta$ is the angle between the two photons and $P_{\mathrm{T}}$ is the transverse momentum of electronpositron pair, $m_{0}$ is the mass of electron and $c$ is the light velocity. ${ }^{3)}$ The angular correlation measurements, therefore, yields the momentum distribution of annihilated electrons, on account of the negligible momentum of thermalized positrons. Figure 4 shows a typical angular correlation apparatus. ${ }^{3)}$

Doppler broadening measurement of positron annihilation (DOBPA) is another method using

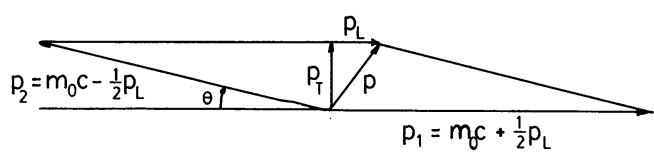

Fig. 3. The vector diagram of the momentum conservation in a positron annihilating with an electron.

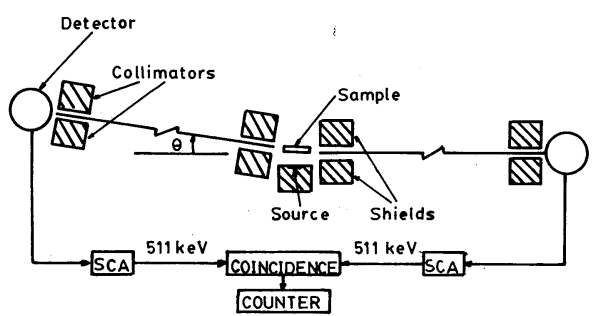

Fig. 4. A typical system diagram for angular correlation measurement.

positron annihilation. The momentum of an annihilated electron similarly causes a Doppler shift in the observed $\gamma$-ray energy spectrum. Instead of the transverse momentum, the longitudinal momentum of electrons causes this Doppler shift $(\Delta E)$, as

$$
\Delta E=c P_{\mathrm{L}} / 2
$$

where $P_{\mathbf{L}}$ is the longitudinal momentum of electron-positron pair. From the line shape of the spectrum, the distribution of the momentum can be evaluated. The system diagram for DOBPA is 


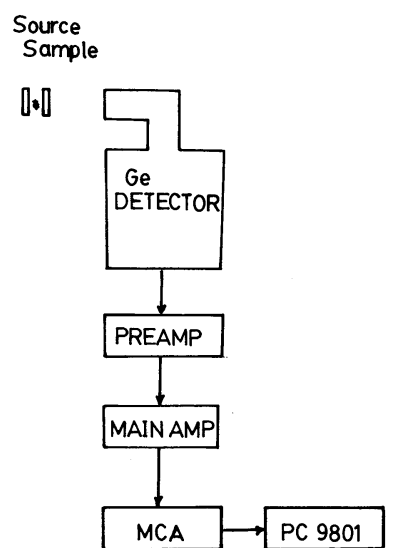

Fig.5. A typical system diagram for DOBPA.

shown in Fig. 5. ${ }^{3), 4)}$

As described above, positron annihilation occurs in the free positron state in the solid or in the trapped state at vacancy-type defects or microvoids. Electrons with low momentum such as conduction or valence electrons usually annihilate with positrons in the trapped state, while those with high momentum such as core electrons annihilate with the free positrons. Therefore, angular correlation measurement and DOBPA of a solid with a high concentration of vacancy-type defects or microvoids show a large ratio of the counts in the center of the spectrum which corresponds to the small Doppler shift.

These positron annihilation measurements have been proved to be powerful and useful tools of studying the momentum distribution of electrons, Fermi surface or vacancy-like defects and microvoids in metals or alkali halides. Compared with other methods such as small angle s̀cattering or electron spin resonance (ESR) of exploring voids or dangling bonds that exist usually on the lattice vacancies, the measurements using positron annihilation sensitively detect microvoids below $10 \AA$ in diameter. This is because positrons are easily trapped even at single vacant lattice sites in a material.

One of the authors, Shizuma, has carried out DOBPA to aluminum, and has successfully estimated the trapping model parameters. ${ }^{5)}$ As temperature increases, the vacancy concentration $\left(C_{\mathrm{v}}\right)$ increases as

$$
C_{\mathrm{v}}=\exp \left(\frac{S_{\mathrm{f}}}{k}\right) \exp \left(-\frac{E_{\mathrm{f}}}{k T}\right)
$$

where $S_{\mathrm{f}}$ and $E_{\mathrm{f}}$ are the formation entropy and enthalpy of a monovacancy, respectively, and $k$ is the Boltzmann constant. ${ }^{3)}$ The temperature dependence of a qualitative line shape parameters $(F(T))$ obtained from DOBPA can be expressed as

$$
F(T)=\frac{F_{\mathrm{f}}^{0}(1+\alpha T)+F_{\mathrm{v}}^{0}(1+\beta T) A \exp \left(-E_{\mathrm{f}} / k T\right)}{1+A \exp \left(-E_{\mathrm{f}} / k T\right)}
$$

where $F_{\mathrm{f}}^{0}(1+\alpha T)$ and $F_{\mathrm{v}}^{0}(1+\beta T)$ are the temperature dependence of the parameters when all positrons annihilate in the free state and in the trapped state, respectively, and $A$ is a constant. By using these equations, vacancy-type defects can be characterized. Many works have been carried out on other metals such as $\mathrm{Zn},{ }^{6)} \mathrm{Cd}^{6}$ or $\mathrm{Co}^{7)}$ as well as $\mathrm{Al}$.

These techniques have been likewise powerful for the study of amorphous metals. Tanigawa et al. ${ }^{8)}$ pointed out that the amorphous states of $\mathrm{Pd}-\mathrm{Si}, \mathrm{Ni}-\mathrm{P}$ or $\mathrm{Cu}-\mathrm{Zr}$ alloys could be described by dense random packing model since no significant difference could be seen between amorphous and crystalline states. Chung and Chen ${ }^{9)}$ have observed glass transition of $\mathrm{Pt}-\mathrm{Ni}-\mathrm{P}$ and $\mathrm{Pd}-$ $\mathrm{Cu}-\mathrm{Si}$ glasses were associated with the sudden increase in line shape parameters of DOBPA.

Lately, the positron studies of materials other than metals, alkali halides, ${ }^{10)}$ oxide glasses, ${ }^{11), 12)}$ oxide crystals, ${ }^{13)-16)}$ organic polymers ${ }^{17), 18}$ and crystalline semiconductors, ${ }^{19)-23)}$ for example, have been reported. The number of works, however, has been apparently less than that for metals, and, especially, little has been reported on amorphous semiconductors such as amorphous silicon. The recent development of the structural investigation into amorphous silicon by positron annihilation is reviewed in the following parts of this paper.

\section{Application of positron annihilation measurements to amorphous silicon}

Since a pioneering work on the effectiveness of the hydrogenation of amorphous silicon (a-Si) for compensating dangling bonds was reported by Spear and LeComber, ${ }^{24)}$ the studies of a-Si and hydrogenated amorphous silicon $(\mathrm{a}-\mathrm{Si}: \mathrm{H})$ have extensively been carried out on account of its great potential of the practical uses, such as solar cells or photoconducting layers in xerography. ${ }^{25)}$ Currently, there are many variants of the preparation method. Ionized-cluster beam deposition, chemical sputtering, thermal chemical vapor decomposition (CVD), glow discharge (GD) decomposition are the techniques commonly used. ${ }^{26)}$

A great deal of works, in order to elucidate electronic properties and structure of them, have been reported. The small angle scattering, ${ }^{27)}$ electron spin resonance (ESR) $)^{28)}$ or scanning electron microscopy ${ }^{26)}$ have been applied to a-Si : $\mathrm{H}$, and the high concentration of dangling bonds and voids have been found. The proton nuclear 
Table 1. Lifetimes for c-Si, a-Si and a-Si : H. ${ }^{33)}$

\begin{tabular}{|c|c|c|c|}
\hline & $\tau 1$ (ps) & $\tau 2(p s)$ & $\tau 3 \quad(p s)$ \\
\hline$c-S i$ & $\sim \quad 125$ & $190 \sim 260$ & $\sim 1300$ \\
\hline$a-S i$ & $150 \sim 230$ & $410 \sim 500$ & 1600220 \\
\hline$a-S i: H$ & $160 \sim 280$ & $400 \sim 550$ & 64008 \\
\hline
\end{tabular}

magnetic resonance (NMR) studies indicate the compositional fluctuation in a-Si: H. ${ }^{29-31)}$ Thereby, the microstructure of a-Si : $\mathrm{H}$ is increasingly interested in. The size and concentration of microvoids may inform us of the details of the microstucture of a-Si : $\mathrm{H}$ or its structural transformation by the treatment such as annealing. However, these small microvoids are hardly detected by the methods except positron annihilation.

Table 1 lists the lifetimes for crystalline, amorphous and hydrogenated amorphous silicon prepared by rf sputtering. ${ }^{21), 32-34)}$ They were sputtered on n-type $(10-20 \Omega \cdot \mathrm{cm})$ single-crystal wafers in an argon or argon +12 at $\% \mathrm{H}_{2}$ atmosphere with the wafers kept at $280^{\circ} \mathrm{C}$. ${ }^{33)}$ The three distinguishable lifetimes can be seen for all samples. For a-Si : $\mathrm{H}$, the lifetime of $6400-8200$ ps seems to be due to ortho-positronium. Positronium (Ps) is the bound positron-electron pair, and ortho-Ps consists of the parallel spin pair (triplet). The diameter enough to form positronium is more than 10 or $20 \AA{ }^{34)}$ although the critical size has not yet been generally determined. This formation of ortho-Ps in the sputtered a-Si : $\mathrm{H}$ was confirmed by the angular correlation measurements by $\mathrm{He}$ et al. ${ }^{33)}$ The ortho-Ps drastically decreases for a-Si to below $1 \%$ of relative intensity, although the peak for the lifetime $\left(\tau_{2}\right)$ located around 450 ps is still intense. This range of lifetime $\left(\tau_{2}\right)$ can be assigned to the quadrivacancy-like microvoids, according to Dannfaer et al. ${ }^{21)}$ For $\mathrm{c}-\mathrm{Si}$, no lifetime peak around 450ps and only a very weak lifetime peak of nearly 1300ps can be observed. These results indicate the size of the microvoids are increased by randomizing structure from c-Si to $\mathrm{a}-\mathrm{Si}$ and by hydrogenation. Incidentally, the spin density in a-Si and a-Si : $\mathrm{H}$ at room temperature are $8.0 \times 10^{19} \mathrm{~cm}^{-3}$ and $4.2 \times 10^{16} \mathrm{~cm}^{-3}$, respectively. From $g$-value $(2.0055)$ and $H_{\mathrm{pp}}(\simeq 7 \mathrm{G})$, the spins are due to the neutral dangling bonds $\left(T_{3}^{0}\right)$ on $\mathrm{Si}$ atoms. A lifetime of approximately 250ps expected for the annihilation between these electrons in the dangling bonds and injected positrons has not been detected. ${ }^{32}$

Figure 6 shows the temperature dependence of relative intensities of lifetimes for sputtered a-Si $: \mathrm{H}^{33)}$ Only the relative intensity $\left(I_{3}\right)$ of the longest lifetime $\left(\tau_{3}\right)$ increases to $400^{\circ} \mathrm{C}$ and then

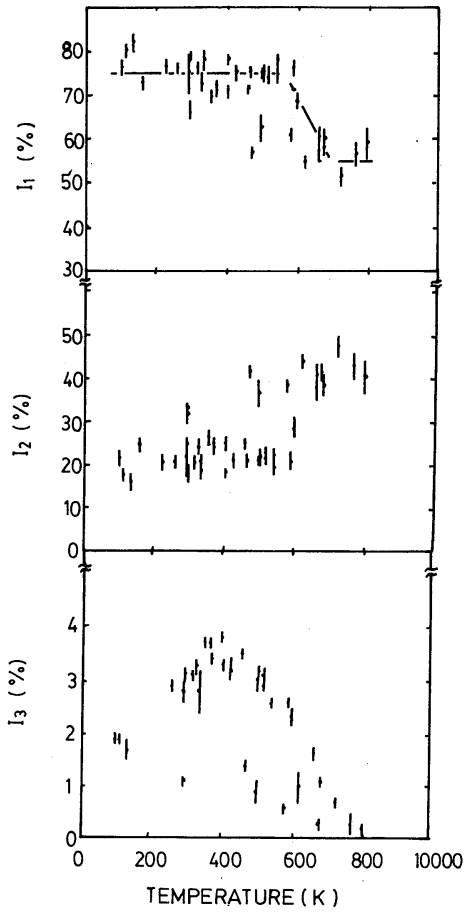

Fig. 6. The temperature dependence of lifetimes for sputtered a-Si : H. ${ }^{33)}$

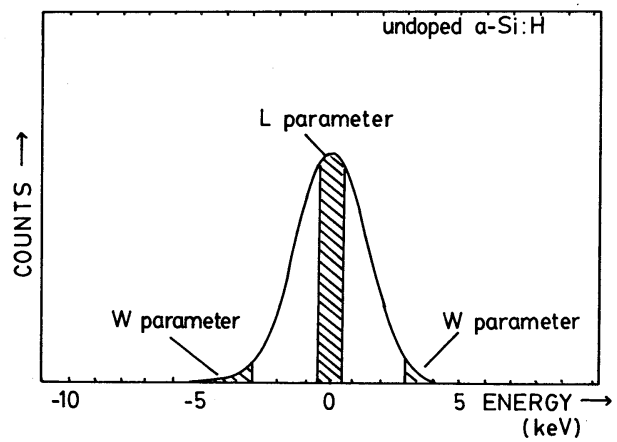

Fig. 7. A typical DOBPA spectrum for a-Si : H prepared at high deposition rate, and two line shape parameters, $L$ and $W$, shown by hatching.

decreases, while others are almost constant to $550^{\circ} \mathrm{C}$. Above $550^{\circ} \mathrm{C}$, lifetime $\left(\tau_{2}\right)$ from quadrivacancy increases from about $20 \%$ to $50 \%$, and , on the other hand, the shortest lifetime $\left(\tau_{1}\right)$ decreases from about $75 \%$ to $55 \%$. He et al. have attributed this phenomena to the temperature dependence of the thermal detrapping and a temperature-dependent trapping cross section. However, the evolution of hydrogens or the reconstruction of the structure should have been taken into account, since the concentration of hydrogens, $\mathrm{Si}-\mathrm{H}$ or $\mathrm{Si}-\mathrm{H}_{2}$ bonds are largely dependent on temperature even below $400^{\circ} \mathrm{C}$.

Besides lifetime measurements, DOBPA has 
also been applied to sputtered a-Si and a-Si : $\mathrm{H} .{ }^{32)}$, 34) Figure 7 illustrates a typical spectrum of the DOBPA for a-Si : H. To analyze the spectra, line shape $(L)$ parameter and wing $(W)$ parameter are commonly used. $L$ parameter is defined as a ratio of integrated counts at the central portion to the total counts, and $W$ parameter is defined as that at both sides of the edge portion to the total counts. In our experiment, we define a spectral range of -0.7 to $0.7 \mathrm{keV}$ as the central portion, those of -7 to $-3 \mathrm{keV}$ and 3 to $7 \mathrm{keV}$ as the edge portions and that of -7 to $7 \mathrm{keV}$ as the total. 2),4),35),36)

Since the Doppler shift is proportional to the longitudinal momentum of the annihilating electrons, these line shape parameters give the distribution of the momentum of the electrons. The trapped positrons usually annihilate with conduction or valence electrons with relatively low momentum, which results in small Doppler shift. Thus, the increase of $L$ parameter corresponds to the increase of the probability of trapping, in the concentrated vacancy-type defects or microvoids. In contrast with it, the $W$ parameter represents the annihilated electrons with high momentum. Namely, the change in $L$ parameter behaves generally in a inversive manner to that in $W$ parameter. Jung et al. ${ }^{32}$ compared $L$ and $S$ parameters of a-Si : H with those of a-Si, where $S$ parameter is defined by $L / W$. Although the different definition for both parameters disturbs the comparison with the present work, they found the relationships of $S_{\mathrm{a}-\mathrm{Si}: \mathrm{H}}>S_{\mathrm{a}-\mathrm{Si}}$ and $L_{\mathrm{a}-\mathrm{Si}: \mathrm{H}}>L_{\mathrm{a}-\mathrm{Si} \cdot}{ }^{{ }^{32)}}$ Consequently, these results give another evidence for the increase of the microvoids by hydrogenation.

The electronic properties and structure are sensitively dependent on the preparation methods as well known. ${ }^{37)} \mathrm{But}$, no systematic work on this dependence by positron annihilation has been carried out yet as far as we know. From a little

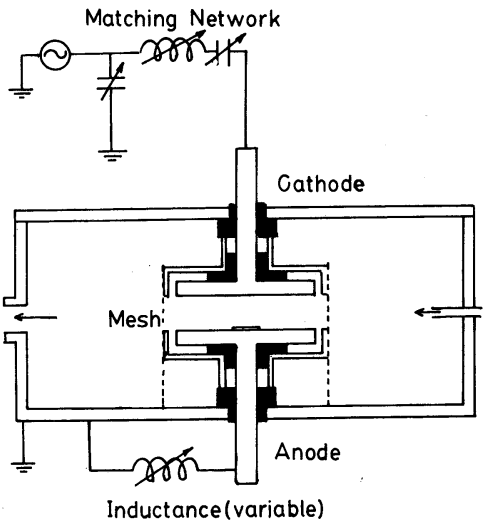

Fig. 8. Experimental system for plasma-enhanced chemical vapor deposition with substrate tuning network. Hatched parts are ceramic insulators.

information we presently have, the formation of ortho-Ps in a-Si : $\mathrm{H}$ by GD is much less than that in $\mathrm{a}-\mathrm{Si}: \mathrm{H}$ by sputtering. ${ }^{38}$

\section{Application of positron annihilation measurements to hydrogenated amorphous silicon prepared at high deposition rate}

A recent strong demand for thin a-Si: $\mathrm{H}$ films is a very high deposition rate in fabricating a-Si : $\mathrm{H}$ devices. ${ }^{25}$ ) From this motivation, several techniques have been developed. For instance, the usage of disilane $\left(\mathrm{Si}_{2} \mathrm{H}_{6}\right)$ or trisilane $\left(\mathrm{Si}_{3} \mathrm{H}_{8}\right)$ instead of silane gas $\left(\mathrm{SiH}_{4}\right)$ enhanced the deposition rate to nearly $6 \mathrm{~nm} / \mathrm{s} .{ }^{39)}$ Electron cyclotron resonance (ECR) plasma ${ }^{40)}$ and hot-wall type symmetric-plasma (HWSP) $)^{41)}$ CVD are also available to accelerate deposition rate to $20 \mathrm{~nm} / \mathrm{s}$ and $8 \mathrm{~nm} / \mathrm{s}$, respectively, at the negligible sacrifice of electronic properties. Newly modified plasmaenhanced CVD by our lab. shown in Fig. 8 likewise increases deposition rate to $6 \mathrm{~nm} / \mathrm{s}$, maintaining high electronic qualities for

Table 2. $\quad L$ and $W$ parameters for c-Si, undoped and B doped a-Si : H prepared at high deposition rate.

\begin{tabular}{|c|c|c|}
\hline Ma $t$ er i a $1 \mathrm{~s}$ & $\mathrm{~L}-\mathrm{p}$ a $\mathrm{r}$ a me $\mathrm{t}$ e $\mathrm{r}$ & $W-p$ a $r$ a $\mathrm{e} t$ e $r$ \\
\hline c r y s t a 1 s i & $0.302 \pm 0.001$ & $0.0264 \pm 0.0032$ \\
\hline $\begin{array}{l}\text { a-S i : } \mathrm{H} \\
\text { deposited at } 30^{\circ} \mathrm{C}\end{array}$ & $0.319 \pm 0.001$ & $0.0209 \pm 0.0025$ \\
\hline $\begin{array}{l}\text { a-S i : H } \\
\text { deposited at } 250^{\circ} \mathrm{C}\end{array}$ & $0.315 \pm 0.001$ & $0.0249 \pm 0.0030$ \\
\hline $\begin{array}{l}\mathrm{B} \text { doped a }-\mathrm{S} \mathrm{i}: \mathrm{H} \\
\text { deposited at } 250^{\circ} \mathrm{C}\end{array}$ & & \\
\hline $\begin{array}{c}\mathrm{B} 2 \mathrm{H}^{6} / \mathrm{S} \mathrm{i} \mathrm{H}^{4}= \\
6.0 \times 10^{-4} \\
\end{array}$ & $0.317 \pm 0.001$ & $0.0220 \pm 0.0028$ \\
\hline 9. $0 \times 10^{-4}$ & $0.317 \pm 0.001$ & $0.0219 \pm 0.0028$ \\
\hline 6. $0 \times 10^{-3}$ & $0.318 \pm 0.001$ & $0.0229 \pm 0.0028$ \\
\hline
\end{tabular}


application. ${ }^{42), 43)}$ In this method, the substrate was placed on the bottom electrode $(12 \mathrm{~cm}$ in diameter) and rf power was supplied to the top electrode through the matching network. The ground mesh surrounding the parallel electrodes was used for confining the plasma and for changing the potential profile between the electrodes. ${ }^{42,433}$ A variable inductance coil connected between the bottom electrode and the grounded chamber forms a resonant circuit together with the capacitance of the sheath existing on the substrate electrodes. ${ }^{44}$ These a-Si : $\mathrm{H}$ films prepared at high deposition rate have aroused an academic interests on the structure as well as a practical interests, because the deposition rate is one of the important factors on the structure of a-Si: $\mathrm{H}$. Actually, the low deposition rate such as $10 \mathrm{pm} / \mathrm{s}$ prefers the formation of microcrystalline hydrogenated silicon $(\mu \mathrm{c}-\mathrm{Si}: \mathrm{H}){ }^{45)}$

The $L$ and $W$ parameters estimated from DOB. PA for a-Si : H prepared by our newly modified plasma-enhanced CVD are listed in Table 2. The peak of para-Ps (spin singlet) is included into $L$ parameter because of very small Doppler shift, and that of ortho-Ps (spin triplet) can be negligible since the observed $\gamma$-ray spectra was well symmetric. As seen in this table, $L$ parameter contains far smaller percentage error in comparison with $W$ parameter. Thus, the following discussion is preferentially focused on $L$ parameter. The $L$ parameter of $\mathrm{c}$-Si is obviously lower than those of a-Si : $\mathrm{H}$ by over 0.010 . Comparing to the usual $L$ parameter distributing 0.25 to 0.5 even from crystalline metals to alkali halides, ${ }^{10)}$ this change of over 0.010 can be expressed as a large difference for the materials consisting of the same elements. A large increase in the microvoid concentration is caused by the randomness of the structure and hydrogenation. This fact agrees with the results for sputtered a-Si: $\mathrm{H}$. The substrate temperature similarly influences $L$ parameter. The undoped a-Si : $\mathrm{H}$ prepared at $30^{\circ} \mathrm{C}$, which contains larger concentration of $\left(\mathrm{Si}-\mathrm{H}_{2}\right)_{n}$ bonds, from infrared spectra, has higher $L$ parameter and lower $W$ paramerer that at $250^{\circ} \mathrm{C}$. The former film shows inferior quality in electrical properties to that at $250^{\circ} \mathrm{C}$. ${ }^{4), 43}$ Thus, the increase of $\left(\mathrm{Si}-\mathrm{H}_{2}\right)_{n}$ bonds in the structure seems to relate to an increase in the microvoids.

Figure 9 shows the temperature dependence of $L$ parameter for undoped a-Si prepared at high deposition rete. To $400^{\circ} \mathrm{C}, L$ parameter is almost inert for annealing, and then slowly increases to $500^{\circ} \mathrm{C}$. Over $500^{\circ} \mathrm{C}$, it steeply decreases as annealing temperature increases. The detailed explanation with the data of the photoluminesc-

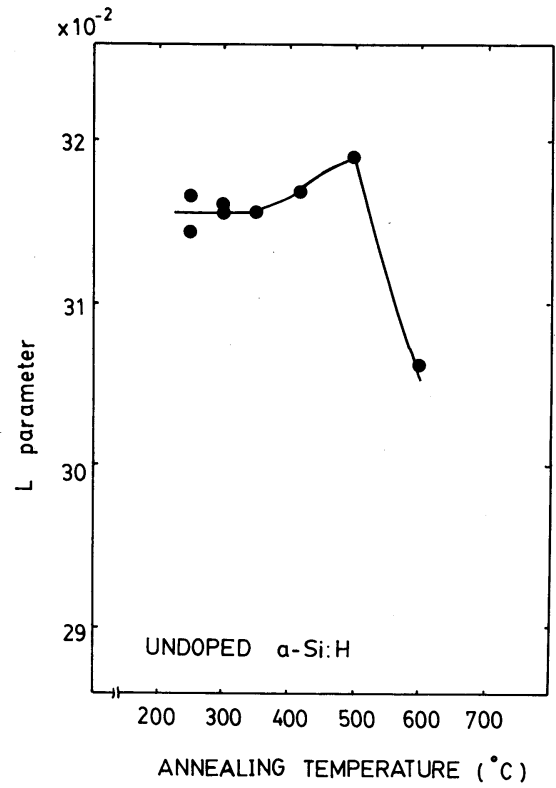

Fig. 9. The concentration of $\mathrm{Si}-\mathrm{H}$ and $\mathrm{Si}-\mathrm{H}_{2}$ bonds estimated from infrared absorption as a function of $\mathrm{B}_{2} \mathrm{H}_{6} / \mathrm{SiH}_{4}$.

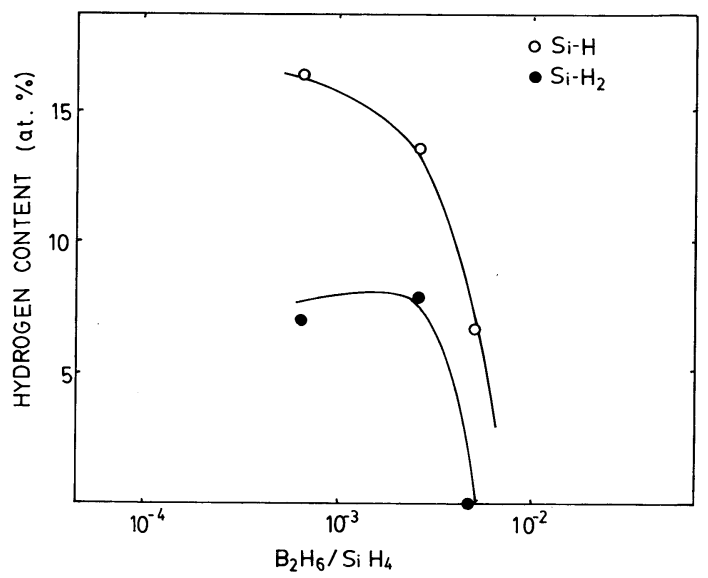

Fig. 10. The relationship between $L$ parameter and annealing temperature for undoped a-Si : $\mathrm{H}$ prepared at high deposition rate.

ence (PL), optical absorption and proton nuclear magnetic resonance are described in our previous papers. ${ }^{4), 41)}$ Briefly, the following interpretation seems to be appropriate. The partial conversion of the $\mathrm{Si}-\mathrm{H}$ configuration to the isolated $\mathrm{Si}-\mathrm{H}_{2}$ to $400^{\circ} \mathrm{C}$ is not associated with the detectable change of the microvoids by DOBPA. Then, the conversion from the isolated $\mathrm{Si}-\mathrm{H}_{2}$ configuration to $\left(\mathrm{Si}-\mathrm{H}_{2}\right)_{n}$, up to $500^{\circ} \mathrm{C}$, is accompanied by the increase of the microvoids. From the X-ray diffraction observations, ${ }^{4,42), 43)}$ the crystallization temperature for undoped a-Si $: \mathrm{H}$ ranges about 
$650^{\circ} \mathrm{C}$, and the value of $L$ parameter decreases towards the value of $\mathrm{c}$-Si. Therefore, the steep decrease over $500^{\circ} \mathrm{C}$ can be ascribed to the structural change relating to crystallization.

With respect to boron doping, only a little increase of $L$ parameter and little dependence on the doping amount are seen. Specifically, the increase of $L$ parameter by boron doping is even smaller than that by substrate temperature down to $30^{\circ} \mathrm{C}$. Figure 10 shows the concentration of $\mathrm{Si}-\mathrm{H}_{2}$ and $\mathrm{Si}-\mathrm{H}$ bonds as a function of $\mathrm{B}_{2} \mathrm{H}_{6} / \mathrm{SiH}_{4}$ gas ratio in preparation. From this figure, it can be pointed out that the concentration of $\mathrm{Si}-\mathrm{H}$

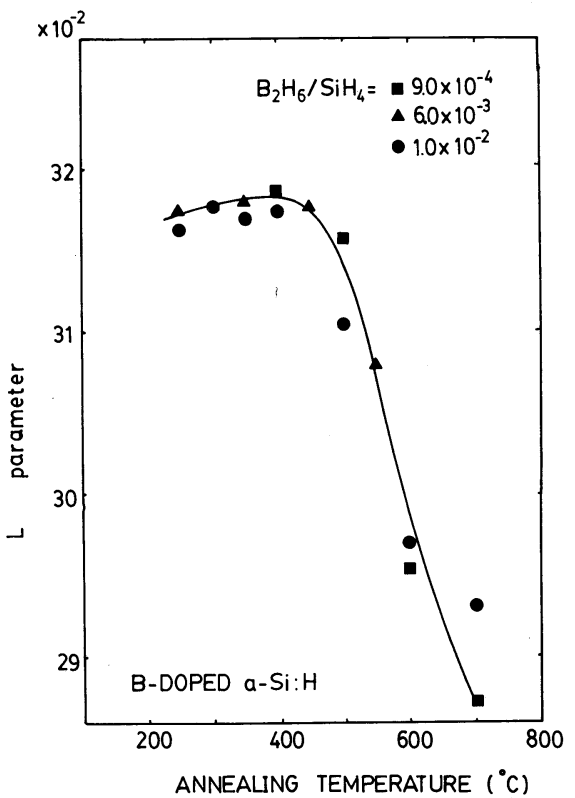

Fig. 11. The relationship between $L$ parameter and annealing temperature for $\mathrm{B}$-doped a-Si : $\mathrm{H}$ prepared at high deposition rate.

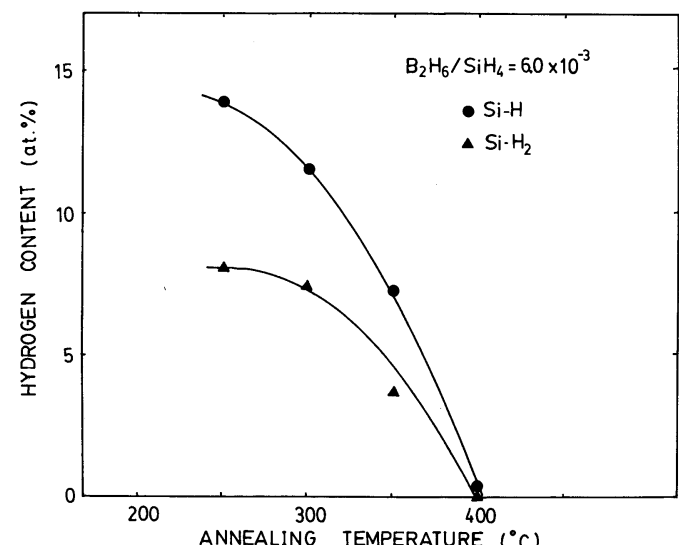

Fig. 12. The concentration of $\mathrm{Si}-\mathrm{H}$ and $\mathrm{Si}-\mathrm{H}_{2}$ bonds estimated from infrared absorption as a function of annealing temperature for B-doped a-Si : $\mathrm{H}$. bonds and accordingly that of total hydrogen decrease as $\mathrm{B}_{2} \mathrm{H}_{6} / \mathrm{SiH}_{4}$ gas ratio increases, and eventually a small concentration of $\mathrm{Si}-\mathrm{H}$ bonds (6-7\%) has been detected at $\mathrm{B}_{2} \mathrm{H}_{6} / \mathrm{SiH}_{4}=6 \times 10^{-}$ ${ }^{3}$. In parallel, the concentration of $\mathrm{Si}-\mathrm{H}_{2}$ bonds disappears at $\mathrm{B}_{2} \mathrm{H}_{6} / \mathrm{SiH}_{4}=6 \times 10^{-3}$. Nevertheless, the spin density estimated from ESR results ${ }^{46}$ is almost constant for each B-doped a-Si : $\mathrm{H}$ samples in this study. ${ }^{47)}$ These little influence to the spin density, in spite of the decrease of hydrogen content and a little increase of the concentration of microvoids can be qualitatively interpreted as follows. The elimination of hydrogen by boron doping presumably compensates the increase of $L$ parameter because of boron, but the difference of the atomic radius between $\mathrm{B}$ and $\mathrm{H}$ may give rise to a small increase of it. ${ }^{46), 47)}$

Figure 11 shows the temperature dependence of $L$ parameter for B-doped a-Si : H prepared at high deposition rate. From this figure, little dependence on $\mathrm{B}_{2} \mathrm{H}_{6} / \mathrm{SiH}_{4}$ ratio can be seen. The $L$ parameter very slowly increases to $450^{\circ} \mathrm{C}$, and then steeply decreases. The flat part in Fig. 9 to $400^{\circ} \mathrm{C}$ for undoped a-Si: $\mathrm{H}$ disappears for Bdoped a-Si: $\mathrm{H}$. The temperature dependence of hydrogen content is shown in Fig. 12 for a representative $\mathrm{B}_{2} \mathrm{H}_{6} / \mathrm{SiH}_{4}$ ratio of $6 \times 10^{-3}$. As seen in this figure, both $\mathrm{Si}-\mathrm{H}$ and $\mathrm{Si}-\mathrm{H}_{2}$ bonds of B-doped a-Si:H monotonically decrease as annealing temperature increases, and undetectable over $400^{\circ} \mathrm{C}$, whereas $\mathrm{Si}-\mathrm{H}_{2}$ content increases to $400^{\circ} \mathrm{C}$ for undoped a-Si : $\mathrm{H}^{4}{ }^{47)}$ That is, hydrogens in $\mathrm{B}$-doped a-Si:H are preferentially eliminated from the samples without contributing to the reconstruction of the structure, ${ }^{4), 45), 48}$ unlike hydrogens in undoped a-Si : $\mathrm{H}$. This difference is probably due to the specific role of hydrogens in B-doped a-Si : H. As pointed out in Figs. 10 and 11 , the boron doping eliminate hydrogens from films. Thus, the reconstruction processes with hydrogen in undoped a-Si : $\mathrm{H}$ seems to disappear in B-doped a-Si : H.

The crystallization temperature determined by $\mathrm{X}$-ray diffraction are approximately $550^{\circ} \mathrm{C}$, and thus the steep decrease can be considered to be related to the crystallization. The starting temperature to decrease is also a little lower than those obtained by X-ray measurement.

\section{Summary}

The recent experimental results and current knowledge on the positron annihilation studies for $\mathrm{a}-\mathrm{Si}$ and $\mathrm{a}-\mathrm{Si}: \mathrm{H}$ are reviewed. Positron annihilation measurements have been proved as useful and powerful methods to investigate vacancy-type defects and microvoids in solids, even for 
amorphous semiconductors. Randomness of the structure and hydrogenation for Si increase the size and the concentration of microvoids. In particular, the quadrivacancy-like microvoids can be seen in a-Si and the formation of positronium has been observed in sputtered a-Si: $\mathrm{H}$. For a- Si : H prepared at high deposition rate, the substrate temperature is one of the important factors on the concentration of microvoids. The boron doping, however, scarcely affect the concentration of microvoids and spin density. Furthermore, the annealing temperature dependence of line shape parameters are different from undoped a-Si. These influences of boron doping can be attributed to the elimination of hydrogens from the structure.

1) S. Tanigawa, "Surface Studies by Positron Annihilation”, Y. Otsuki Ed., Kyouritsu Shuppan (1983) pp. 61-136.

2) F. Nishiyama, K. Shizuma, H. Hasai and M. Nishi, Bulletin Fac. Eng. Hiroshima University, 29, 149 (1981).

3) P. Hantojärvi and A. Vehanen, "Introduction to Positron Annihilation" in 'Positrons in Solids', P. Hantojärvi Ed., Springer-Verlag (1979) pp. 1-23.

4) M. Watanabe, H. Nasu, K. Shizuma, T. Imura, Y. Osaka and H. Hasai, Mem. Fac. Eng. of Hiroshima Univ., 29, 11 (1987).

5) K. Shizuma, E. Hashimoto, Y. Yoshizawa and T. Kino, J. Phys. F: Metal Phys., 11, 2461 (1981).

6) B. T. A. McKee, W. Triffsäuser and A. T. Stewart, Phys. Rev. Lett., 28, 358 (1972).

7) S. M. Kim and W. J. L. Buyers, J. Phys., F8, L103 (1978).

8) S. Tanigawa, K. Hinode, R. Nagai, K. Kanbe, M. Doyama and N. Shiotani, Phys. Stat. Sol. (a), 51, 249 (1979).

9) S. Y. Chung and H. S. Chen, in "Positron Annihilation", P. G. Coleman, S. C. Sharma and L. M. Diana Eds., North Holland Publ. (1982) p. 590.

10) K. Shizuma, Nuclear Instruments and Methods, 173, 395 (1980).

11) S. M. Kim and W. J. L. Buyers, J. Phys., C11, 101 (1978).

12) S. G. Usmar, H. Rawson and R. N. West, in "Positron Annihilation", P. G. Coleman, S. C. Sharma and L. M. Diana Eds., North Holland Publ. (1982) p. 660.

13) T. Mitsuhashi, M. Noguchi, T. Chiba and N. Tsuda, J. Phys. Soc. Japan, 30, 1206 (1971).

14) M. Noguchi, T. Mitsuhashi, T. Chiba, T. Tanaka and N. Tsuda, J. Phys. Soc. Japan, 32, 1242 (1972).

15) N. Tsuda, T. Mitsuhashi and T. Chiba, J. Phys. Soc. Japan, 36, 523 (1974).

16) M. Noguchi, N. Kimizuka, T. Chiba and N. Tsuda, $J$. Phys. Soc. Japan, 34, 661 (1973).

17) P. T'seng, S. Chang and S. Chuang, ibid., 730.

18) C. Dane and M. Kwete, ibid., 663.

19) Y. Iwasa, A. Uedono, S. Tanigawa and T. Suzuki, Radioisotopes, 34, 195 (1985).

20) S. Dannefaer, D. Kerr and B. G. Hogg, J. Appl. Phys., 54, 155 (1983).

21) S. Dannefaer, G. W. Dean, D. P. Kerr and B. G.
Hogg, Phys. Rev., B14, 2709 (1976).

22) K. Kitagawa, T. Aoki, H. Furuta, Y. Suzuki and M. Doyama, Extended Abstracts (The 47th Autumn Meeting, 1986), The Japan Society of Applied Physics, 771.

23) E. Kuramoto, S. Takeuchi, M. Noguchi, T. Chiba and N. Tsuda, J. Phys. Soc. Japan, 34, 103 (1973).

24) W. E. Spear and P. G. LeComber, Solid State Commun., 17, 1193 (1975)

25) K. Imura, "Amorphous Silicon Thin Films" in 'Technical Reports of Thin Film Processing', Realize Co. Ltd. (1986) p. 265.

26) For instance, "Hydrogenated Amorphous Silicon: Part A (Preparation and Structure)", "Semiconductors and Semimetals" Vol. 21, J. I. Pankove Ed., Academic Press Inc. (1984).

27) R. Bellissent, A. Chenevas-Paule and M. Roth, Physica $B, 117 \& 118,941$ (1983).

28) J. C. Knights and G. Lucovsky, CRC Crit. Rev. Solid State Mater. Sci., 9, 211 (1980).

29) W. E. Carlos and P. C. Taylor, Phys. Rev. Lett., 45, 358 (1980).

30) J. A. Reimer, R. W. Vaughan and J. C. Knights, Solid State commun., 37, 161 (1981).

31) S. Ueda, M. Kumeda and T. Shimizu, Jpn. J. Appl. Phys., 20, 6 (1981).

32) A. Jung, L. Shi, G. Liu, J. Xiong, B. Cao, W. Yu, H. Jiang, J. Song, K. Long and D. Adler, J. Non-Cryst. Solids, 74, 19 (1985).

33) Y. J. He, M. Hasegawa, R. Lee, S. Berko, D. Adler and A. Jung, Phys. Rev., B33, 5924 (1986).

34) A. Jung, Y. Wang, G. Liu, J. Xiong, B. Cao, W. Yu, and D. Adler, J. Non-Cryst. Solids, 74, 19 (1985).

35) M. Watanabe, H. Nasu, K. Shizuma, T. Imura, Y. Osaka and H. Hasai, Extended Abstracts (The 47th Autumn Meeting, 1986), The Japan Society of Applied Physics, 842.

36) M. Watanabe, H. Nasu, K. Shizuma, S. Makida, M. Ueda, T. Imura, Y. Osaka and H. Hasai, Extended Abstracts (The 34th Spring Meeting, 1987), The Japan Society of Applied Physics and Related Societies, 221.

37) For Instance, see "The Physics of Hydrogenated Amorphous Silicon", J. D. Joannopolous and G. Lucousky Ed., Springer, New York (1984).

38) F. Itoh, personal communication.

39) H. Koinuma, H. Natsuaki, K. Fueki, K. Sato, H. Hirano and K. Isogawa, Technical Digest of the International PVSEC-1, Kobe, 743.

40) S. Kato and T. Aoki, J. Non-Cryst. Solids, $77 \& 78,813$ (1985).

41) T. Shimoda, N. Nakamura, S. Matsubara, H. Itoh, S. Muramatsu and M. Morigaki, Technical Digest of the International PVSEC-1, Kobe, 445.

42) T. Hamasaki, M. Ueda, A. Chayahara, M. Hirose and Y. Osaka, Appl. Phys. Lett., 44, 600 (1984).

43) T. Hamasaki, M. Ueda, A. Chayahara, M. Hirose and Y. Osaka, Appl. Phys. Lett., 44, 1049 (1984).

44) J. S. Logan, IBM J. Res. Dev., 14, 172 (1970).

45) Y. Osaka Kotai-Butsuri., 20, 560 (1985).

46) T. Imura, H. Nasu, K. Shizuma, Y. Osaka and H. Hasai, Proc. 2nd KUR Conf. "Studies of semiconductors by research reactor”, 1986.

47) H. Nasu, M. Watanabe, K. Shizuma, S. Makida, M. Ueda, T. Imura, Y. Osaka and H. Hasai, J. Non-Cryst. Solids, in press.

48) M. Ueda, A. Chayahara, T. Nakashita, T. Imura and Y. Osaka, Jpn. J. Appl. Phys., 24, 795 (1985). 